\title{
Surface Energy Balance of the NCEP MRF and NCEP-NCAR Reanalysis in Antarctic Latitudes during FROST*
}

\author{
KEITH M. HINES \\ Polar Meteorology Group, Byrd Polar Research Center, Ohio State University, Columbus, Ohio \\ ROBERT W. GRUMBINE \\ National Centers for Environmental Prediction, Camp Springs, Maryland \\ DAVID H. BROMWICH \\ Polar Meteorology Group, Byrd Polar Research Center and Atmospheric Sciences Program, and Department of Geography, \\ Ohio State University, Columbus, Ohio \\ RichaRd I. CULLATHER \\ Polar Meteorology Group, Byrd Polar Research Center, Ohio State University, Columbus, Ohio
}

(Manuscript received 16 March 1998, in final form 10 March 1999)

\begin{abstract}
The surface energy budget in Antarctic latitudes is evaluated for the medium-range numerical weather forecasts produced by the National Centers for Environmental Prediction (NCEP) and for the NCEP-National Center for Atmospheric Research reanalysis project during the winter, spring, and summer special observing periods (SOPs) of the Antarctic First Regional Observing Study of Troposphere project. A significant change in the energy balance resulted from an extensive model update beginning with the forecasts initialized on 11 January 1995 during the summer SOP. Both the forecasts and the reanalysis include significant errors in the surface energy balance over Antarctica. The errors often tend to cancel and thus produce reasonable surface temperature fields. General errors include downward longwave radiation about $30-50 \mathrm{~W} \mathrm{~m}^{-2}$ too small. Lower than observed cloudiness contributes to this error and to excessive downward shortwave radiation at the surface. The model albedo over Antarctica, about $75 \%$, is lower than that derived from observations, about $81 \%$. During the polar day, errors in net longwave and net shortwave radiation tend to cancel. The energy balance over Antarctica in the reanalysis is, in general, degraded from that of the forecasts.

Seasonal characteristics of the surface energy balance include cooling over East Antarctica and slight warming over West Antarctica during NCEP forecasts for the winter SOP. Wintertime surface warming by downward sensible heat flux is larger than observations by $21-36 \mathrm{~W} \mathrm{~m}^{-2}$ and tends to balance the excessive longwave cooling at the surface. During the spring SOP, forecast sensible heat flux produces an excessive heating contribution by about $20 \mathrm{~W} \mathrm{~m}^{-2}$. Latent heat flux during the Antarctic winter for the reanalysis is at least an order of magnitude larger than the very small observed values.
\end{abstract}

\section{Introduction}

This paper examines the surface energy balance in high southern latitudes for the operational mediumrange weather forecasts produced by the National Centers for Environmental Prediction (NCEP, formerly the

\footnotetext{
* Byrd Polar Research Center Contribution Number 1078.
}

Corresponding author address: Keith M. Hines, Polar Meteorology Group, Byrd Polar Research Center, 1090 Carmack Road, Columbus, OH 43210-1002.

E-mail: hines@polarmet1.mps.ohio-state.edu
National Meteorological Center) during the Antarctic First Regional Observing Study of the Troposphere (FROST). Additionally, the balance is evaluated for the NCEP-National Center for Atmospheric Research (NCAR) reanalysis project. The Antarctic continent, being the coldest and driest place on Earth, presents unique challenges for global model forecasts. The climate of Antarctica is highly complex (Schwerdtfeger 1984; Dolgin 1986), and the troposphere over the high Antarctic plateau exhibits a combination of unique physical phenomena. These features include surface air temperatures routinely below $-50^{\circ} \mathrm{C}$ (Keller et al. 1989), water vapor abundances rarely above 0.6 precipitable $\mathrm{mm}$ (Zav'yalova 1986), clear-sky precipitation (Miller 1974; 
Smiley et al. 1980), and a radiative cooling effect of $\mathrm{CO}_{2}$ rather than a warming effect (Hanel et al. 1972). The increased observations during the recent FROST project provide a unique opportunity to evaluate regional model performance.

In high southern latitudes, the performance of operational numerical analyses and forecasts is limited by a variety of obstacles including the scarcity of available data and communications problems associated with long distances and aurora effects. The above-mentioned extreme weather phenomena and sharp topographic contrasts also create unique difficulties for Antarctica. These factors result in forecasts and analyses that are of poorer quality compared with other parts of the world (Bourke 1996). This problem has been addressed by the international Scientific Committee on Antarctic Research Working Group on Physics and Chemistry of the Atmosphere by advancing the FROST project as a research and data gathering exercise to evaluate the potential for improving the present situation (Bromwich and Smith 1993; Turner et al. 1996).

The primary goal of FROST is to examine the performance of operational analyses and forecasts for Antarctica and the surrounding sea ice zone during three 1-month-long special observing periods (SOPs): (a) SOP-1 (winter) during July 1994, (b) SOP-2 (spring) during 15 October-15 November 1994, and (c) SOP-3 (summer) during January 1995 (Bromwich and Smith 1993; Turner et al. 1996). The U.S. component of this project is an evaluation of analyses and forecasts produced by NCEP. Improvements in these numerical products are a priority for NCEP, due to both the need for reliable global atmospheric numerical analyses in climate research and NCEP's hemispheric obligations for weather prediction, which extend to South America. Additionally, the U.S. Navy's withdrawal from Antarctic missions in March 1998 after 42 years of service and the subsequent transfer of traditional support functions to civilian contractors will ultimately lead to an increased reliance on civilian weather centers (Augustine et al. 1997).

In this paper, we shall focus on the boundary layer features forecast and analyzed by NCEP. Near-surface and boundary layer conditions play a uniquely dominant role in the atmospheric circulation over Antarctica. Physical processes within the lowest few hundred meters of the atmosphere, primarily the near-surface katabatic wind regime, produce the most significant forcing of the atmospheric flows (e.g., Parish 1988). Consequently, the accurate reproduction of near-surface conditions is essential for the NCEP model. Section 2 provides an overview of the NCEP Global Data Assimilation System and the operational Global Spectral Model. In section 3, an overview is presented of the NCEP reanalysis. In section 4 , the accuracy of the surface energy balance of the NCEP operational forecasts for SOP-1 is detailed. Section 5 provides the evaluation of the surface energy balance for SOP-2 and SOP-3. The surface energy balance of the NCEP reanalysis is evaluated in section 6 . A summary of the results is presented in section 7 .

\section{NCEP operational forecasts during FROST}

\section{a. Model description}

The NCEP operational Global Spectral Model is run for the production of several forecast products including the medium-range forecast (MRF), the aviation forecast, and parallel ensemble forecasts produced from initial condition perturbations. The model includes parameterizations of the major physical processes including convection, large-scale precipitation, shallow convection, gravity wave drag, radiation with diurnal cycle and interaction with clouds, boundary layer physics, interactive surface hydrology, and horizontal and vertical diffusion (Kanamitsu 1989; Kanamitsu et al. 1991). Recent changes in the NCEP analysis-forecast system listed in Caplan et al. (1997) include updated radiation every $3 \mathrm{~h}$, inclusion of Arakawa-Schubert convection, and increased vertical resolution to 28 layers. All of these updates were implemented prior to the FROST SOPs. A highly significant model update was implemented in January 1995 during SOP-3. The update involved parameterizations for clouds, surface physics, sea ice physics, as well as changes in the analysis system (Kalnay et al. 1996). The improved diagnostic cloud scheme resulted in more realistic outgoing longwave radiation (Campana et al. 1994). The new soil model resulted in more realistic surface temperature and summertime precipitation (Pan and Mahrt 1987). The horizontal resolution is T126 (about $105 \mathrm{~km}$ ), which is approximately equivalent to $1^{\circ} \times 1^{\circ}$ resolution. In the vertical, 28 sigma levels are included. The 7-day forecasts examined here are run daily from 0000 UTC. A significant obstacle to evaluation of the operational model is that it is routinely modified based on research efforts and operational considerations. The FROST project encompasses the performance of several operational models; it was not possible to devise SOPs to accommodate periodic changes to all models examined.

\section{b. Boundary layer}

A significant update to the MRF surface physics occurred during SOP-3. The revised parameterizations are described by Betts et al. (1996). This more recent version of the MRF was used for the NCEP-NCAR reanalysis. Further revisions to the boundary layer (Hong and Pan 1996; Caplan et al. 1997) have been implemented afterward and do not influence the forecasts and analyses considered by this paper. The version of the MRF used for the reanalysis includes five layers in the lowest $1000 \mathrm{~m}$ of the atmosphere, with the lowest layer about $70 \mathrm{~m}$ thick near Antarctica. The lowest model layer is assumed to be the surface layer. The Monin- 
Obukhov similarity profile is applied at this layer based on Miyakoda and Sirutis (1986), with modifications for very stable and very unstable conditions. King (1990) discusses winter observations from Halley station that suggest surface boundary layer parameterizations are best applied locally for a much shallower layer than used by the MRF. He finds that surface-layer parameterizations can lose accuracy at levels above about $5 \mathrm{~m}$ when the stratification is highly stable. The MRF calculates turbulent exchange coefficients and applies bulk aerodynamic formulas for the surface fluxes. Above the surface, a local stability dependent diffusion scheme is used to define the eddy diffusivities (Louis 1979). The MRF also includes the two-layer soil model of Mahrt and Pan (1984) and Pan and Mahrt (1987) with minor modifications based on Pan (1990).

Most surface energy balance terms are classified as $\mathrm{C}$ variables, which are completely determined by the model and only indirectly influenced by the observations during the initialization (Kalnay et al. 1996). Thus the surface energy balance provides a good means to test the physics of the MRF. The surface energy balance is given by

$$
\begin{aligned}
I=C_{s} \frac{\partial T_{s}}{\partial t}= & (1-\alpha) S(\downarrow)+L(\downarrow)-\sigma T_{s}^{4}+G \\
& -\beta L_{v} E_{p}+S,
\end{aligned}
$$

where $I$ is the net energy balance, $C_{s}$ is heat capacity, $\alpha$ is the albedo, $S(\downarrow)$ is the downward shortwave flux, $L(\downarrow)$ is the downward longwave flux, $\sigma$ is the StefanBoltzmann constant, $T_{s}$ is surface temperature, $G$ is upward ground heat flux, $\beta$ is moisture availability, $L_{v}$ is latent heat of vaporization or sublimation, $E_{p}$ is potential evaporation, and $S$ is downward sensible heat flux. In (1), ground heat flux and sensible heat flux are defined with the opposite sign of the usual convention so that each are positive when contributing to surface warming. The method of determining albedo over sea ice is given by Grumbine (1994). The moisture availability over ice and snow surfaces and the surface emissivity are taken as unity. As the significant changes to the NCEP model occurred during SOP-3, we shall limit our evaluation of that period.

\section{c. Synoptic evaluation}

As a complement to this study, an evaluation of the NCEP Global Spectral Model forecasts for the July 1994 SOP was performed by Bromwich et al. (1999, this issue, hereafter referred to as BCG). They suggested that deficiencies in the model initial fields result in substantial model drift. Several meteorological fields, including surface pressure and surface temperature, undergo adjustments during the 7-day forecast period. In the average of the forecast initialization fields for the polar night over Antarctica, the surface inversion is about half its observed strength. The largest error found by $\mathrm{BCG}$ in the initial tropospheric temperature profile is at the surface where temperatures are about $7 \mathrm{~K}$ too warm. Surface cooling and midtropospheric warming during the forecast improve the intensity of the MRF inversion. The katabatic winds over the continent are reasonably well produced in the NCEP analyses (0-h forecast), but the barrier winds east of the Antarctic Peninsula are not captured. Inadequate parameterization of horizontal diffusion leads to spurious cloud streets surrounded by dry areas over Antarctica. An update of the MRF during November 1997 has corrected this problem. Furthermore, BCG found that modeled precipitation minus evaporation is in excess of water substance available from atmospheric moisture convergence.

\section{NCEP-NCAR reanalysis}

As a prime component of the Climate Data Assimilation System project, NCEP and the National Center for Atmospheric Research (NCAR) have cooperated to produce global reanalyses of atmospheric fields from 1946 to the present with the same modern assimilation system (Kalnay et al. 1993, 1996). This avoids the climate jumps believed to be included in the standard NCEP analysis due to many model updates. The reanalysis should be valuable for many purposes (e.g., Trenberth and Olson 1988). This is particularly true of high southern latitudes, where the scarcity of data necessitates a complete assimilation of all meteorological observations available, including satellite data, to achieve an accurate depiction of the atmosphere. The NCEP-NCAR reanalysis was performed with a 28 -level T62 version (about $210 \mathrm{~km}$ ) of the NCEP global operational model implemented January 1995 during SOP-3. The analysis system includes spectral statistical interpolation, complex quality control of rawinsonde data, optimal interpolation-based quality control of all other data, improved averages by optimal averaging, optimal sea surface temperature reanalysis, and one-way coupled ocean model four-dimensional assimilation from 1982 onward. The reanalysis also includes 8-day forecasts initiated every 5 days. It is important that the reanalysis is carefully analyzed, and any deficiencies are detailed so that corrections can be applied in the future. Updated reanalyses by NCEP are planned approximately every five years.

Observational stations over the Antarctic continent and adjacent parts of the Southern Hemisphere are displayed in Fig. 1. The high southern latitudes are an extremely data-sparse region. Nevertheless, highly valuable synoptic information is gained at existing sites. A recent decline in the total number of manned stations over Antarctica has been offset by an increasing number of automatic weather stations (AWS; Stearns et al. 1993). Most of the upper-air network (open circles) is confined to the perimeter of East Antarctica and the Antarctic Peninsula, with two stations poleward of $75^{\circ} \mathrm{S}$, at McMurdo and the South Pole. Over the oceans, data 


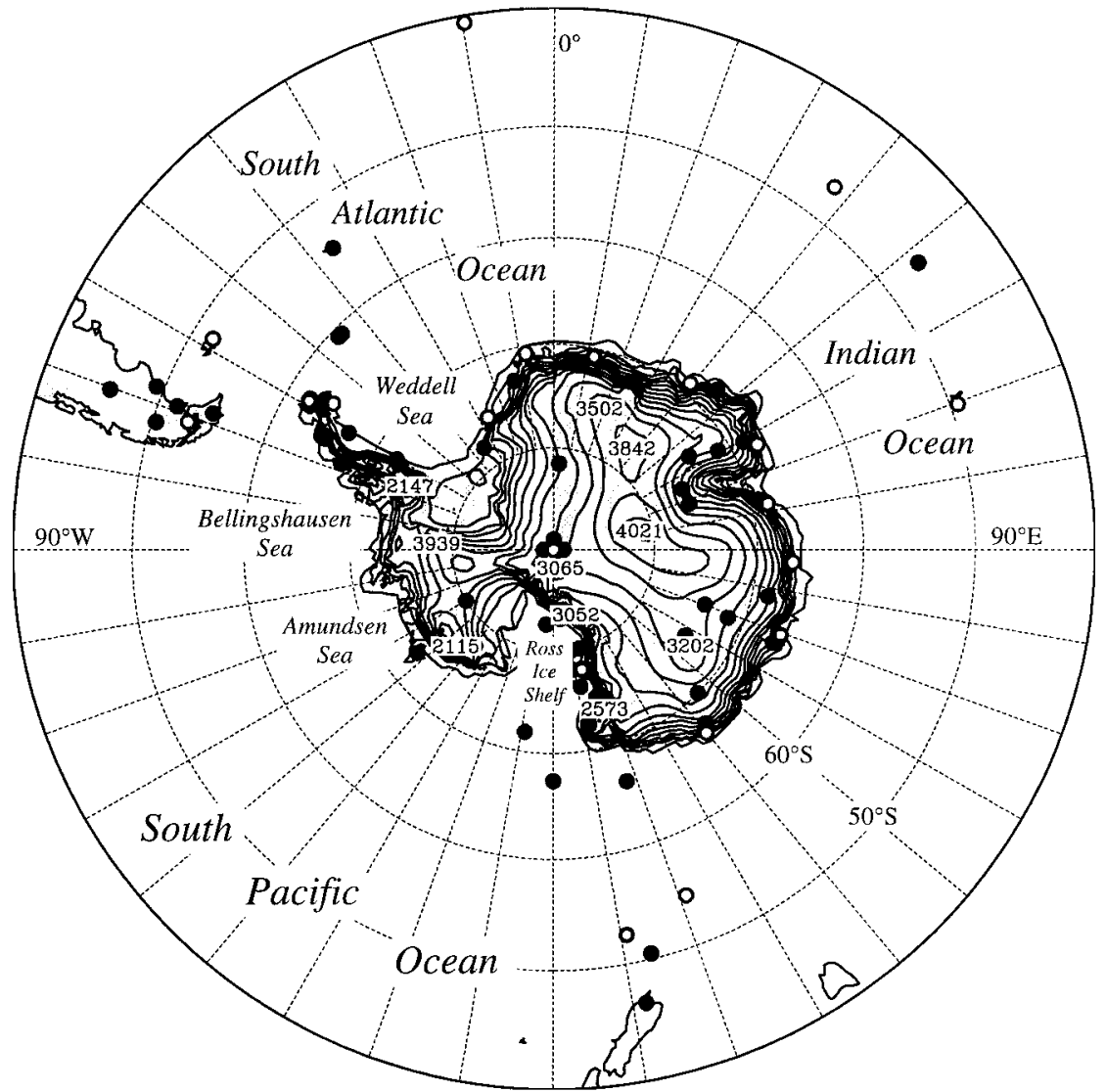

FIG. 1. Map of the Southern Hemisphere poleward of $40^{\circ} \mathrm{S}$ showing the distribution of the surface station network (solid circles) and rawinsonde stations (open circles) in the FROST database, and contours of the Antarctic topography (Drewry 1983) in 300-m increments.

are available from algorithms applied to satellite data (Turner et al. 1996) and from drifting buoys in the western Ross and Weddell Seas. Cullather et al. (1997a) give an evaluation of the success of the NCEP operational analysis from 1985 to 1994 . The NCEP operational analysis during the FROST winter SOP is discussed in detail by BCG.

\section{NCEP operational forecasts for July 1994}

The surface energy balance for Antarctic latitudes is perhaps simplest during the middle of the long polar night due to the lack of both solar shortwave radiation and the induced diurnal cycle. Twice-daily NCEP meteorological fields should present a good picture of the Antarctic energy balance produced by the forecast model during the austral winter. Except in the vicinity of the South Pole, this may not be the case during the polar day when fields every $12 \mathrm{~h}$ may not adequately represent the diurnal cycle. For simplicity, therefore, we begin the evaluation of NCEP operational forecasts with the wintertime SOP during July 1994. This SOP included a series of strong blocking events in the central and eastern Pacific. A basic review of the synoptic forecast skill of the MRF during this time is given by BCG. In the following discussion, we shall concentrate on features related to the surface energy balance.

Figure 2a displays the average of the surface temperature forecasts for day 0.5 in the region south of $60^{\circ} \mathrm{S}$. It was noted by BCG that the analysis (day 0) surface temperature was as much as $7 \mathrm{~K}$ too warm over the interior of Antarctica. This contributed to an analysis inversion strength roughly half that found by Phillpot and Zillman (1970). Thus the static stability will be significantly underrepresented within the MRF boundary layer formulation. Interior surface temperatures cool slightly prior to day 0.5 of the forecast (BCG), producing a slightly stronger inversion over Antarctica. The surface cooling continues during the forecast over East Antarctica, except along the coast from $75^{\circ}$ to $145^{\circ} \mathrm{E}$ (Fig. 2b). Between day 0.5 and day 7.0, temperatures fall $2-8 \mathrm{~K}$ over the East Antarctic plateau and 2-5 K over the central Ross Ice Shelf. Interestingly, surface temperature warms over this period by about $2-6 \mathrm{~K}$ over West Antarctica, and by as much as $8 \mathrm{~K}$ over the southern Ronne-Filchner Ice Shelf. Except for the warming in the Weddell Sea, the sea-ice region generally under- 

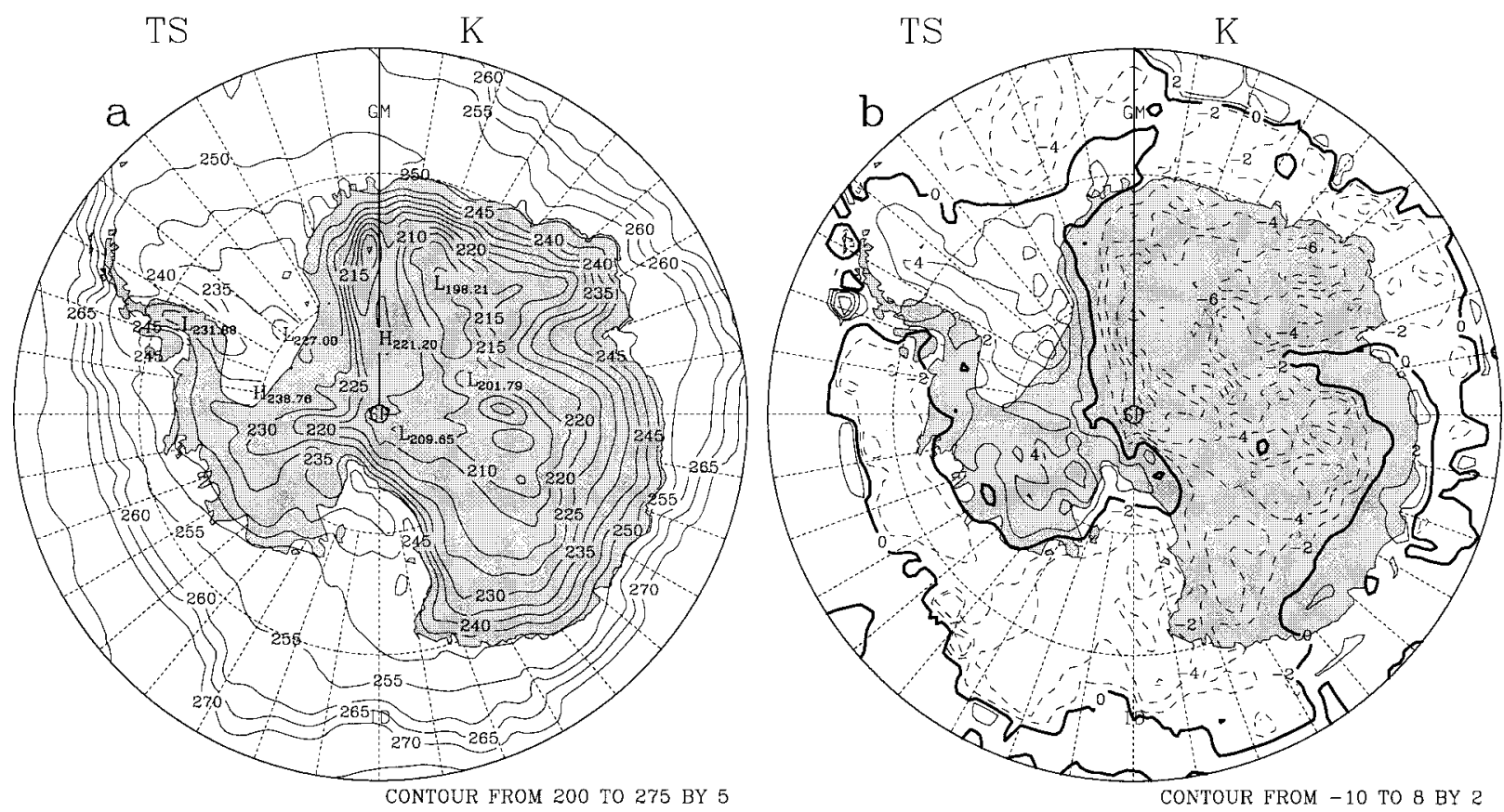

FIG. 2. Average surface temperature (K) for operational forecasts during FROST SOP-1 (July 1994) by the NCEP MRF model for (a) day 0.5 , and (b) the difference between day 7.0 and day 0.5. Contour interval is $5 \mathrm{~K}$ in (a) and $2 \mathrm{~K}$ in (b). Negative contours are dashed. Grid lines are shown for every $10^{\circ}$ of latitude and longitude. Thick contour is 0 .

goes a moderate cooling during the 7-day forecast period.

To detail the differences between the surface energy balance for West and East Antarctica, forecast output fields are spatially averaged for both areas. Averages are derived by choosing from a longitude-latitude grid 971 data points over West Antarctica north of $85^{\circ} \mathrm{S}$ and 5659 data points over East Antarctica. The points are weighted by the cosine of latitude. The averages exclude grid points over the Antarctic Peninsula east of $80^{\circ} \mathrm{W}$

TABLE 1. NCEP operational forecast surface energy balance, Jul 1994 SOP-1. Values are in $\mathrm{W} \mathrm{m}^{-2}$ unless otherwise noted.

\begin{tabular}{|c|c|c|c|c|}
\hline Location and time & $\begin{array}{c}\text { West } \\
\text { Antarctica } \\
\text { day } 0.5\end{array}$ & $\begin{array}{c}\text { West } \\
\text { Antarctica } \\
\text { day } 7.0\end{array}$ & $\begin{array}{c}\text { East } \\
\text { Antarctica } \\
\text { day } 0.5\end{array}$ & $\begin{array}{c}\text { East } \\
\text { Antarctica } \\
\text { day } 7.0\end{array}$ \\
\hline Longwave up & -173.8 & -183.9 & -138.1 & -130.8 \\
\hline Longwave down & +125.9 & +138.3 & +80.8 & +79.4 \\
\hline Net longwave & -47.8 & -45.7 & -57.3 & -51.4 \\
\hline Shortwave up & 0 & 0 & -0.1 & 0.0 \\
\hline Shortwave down & 0 & 0 & +0.2 & 0.0 \\
\hline Net shortwave & 0 & 0 & +0.1 & 0.0 \\
\hline Net radiation & -47.8 & -45.7 & -57.2 & -51.4 \\
\hline Sensible heat* & +40.9 & +42.3 & +56.6 & +44.8 \\
\hline Latent heat* & -0.8 & -1.1 & -2.6 & -2.2 \\
\hline Flux from snowpack & +7.6 & +3.6 & +2.4 & +8.2 \\
\hline Net balance & -0.2 & -0.8 & -0.7 & -0.5 \\
\hline Surface temp $\left({ }^{\circ} \mathrm{C}\right)$ & -38.3 & -35.2 & -52.1 & -55.7 \\
\hline $2-\mathrm{m}$ temp $\left({ }^{\circ} \mathrm{C}\right)$ & -36.5 & -33.5 & -50.5 & -53.8 \\
\hline 10-m wind speed $\left(\mathrm{m} \mathrm{s}^{-1}\right)$ & 4.5 & 4.8 & 6.8 & 5.5 \\
\hline Midlevel cloud (\%) & 24.6 & 32.9 & 19.8 & 20.0 \\
\hline
\end{tabular}

* Sign is reversed from standard convention. or over sea ice. Table 1 displays terms related to the area-average energy balance for both East and West Antarctica. The sign conventions for latent, sensible, and snowpack heat fluxes are opposite those of the standard convention. Thus, positive (negative) values in Table 1 indicate a contribution to surface warming (cooling). Figure 3 shows the time evolution of some of the fields from Table 1. During the forecast time period, downward longwave radiation is approximately constant over East Antarctica and increases by $12.4 \mathrm{~W} \mathrm{~m}^{-2}$ between days 0.5 and 7.0 over West Antarctica. The latter probably represents an improvement during the course of the forecast. The changes in downward longwave radiation are well correlated with those of midlevel cloudiness (not shown). Forecast cloudiness is, in general, small over Antarctica, with much larger cloud amounts at middle levels than at upper or low levels. For West Antarctica, the midlevel cloudiness increases from $24.6 \%$ at day 0.5 to $35.8 \%$ at day 3.0 before decreasing slightly to $32.9 \%$ at day 7.0. Over East Antarctica, the midlevel cloudiness is smaller, fluctuating between $18.5 \%$ and $22.3 \%$ during the forecast period. A slight amount of shortwave radiation reaches the near-coastal regions of East Antarctica at about local noon. The primary energy balance, however, is between net longwave radiation and sensible heat flux. The initially positive contribution of heat flux from within the snowpack to the surface (Fig. 3c) decreases with time for West Antarctica as the surface warms by $3.1 \mathrm{~K}$ from day 0.5 to day 7.0, while the contribution from the snowpack for East Antarctica increases as the surface cools by $3.6 \mathrm{~K}$. 

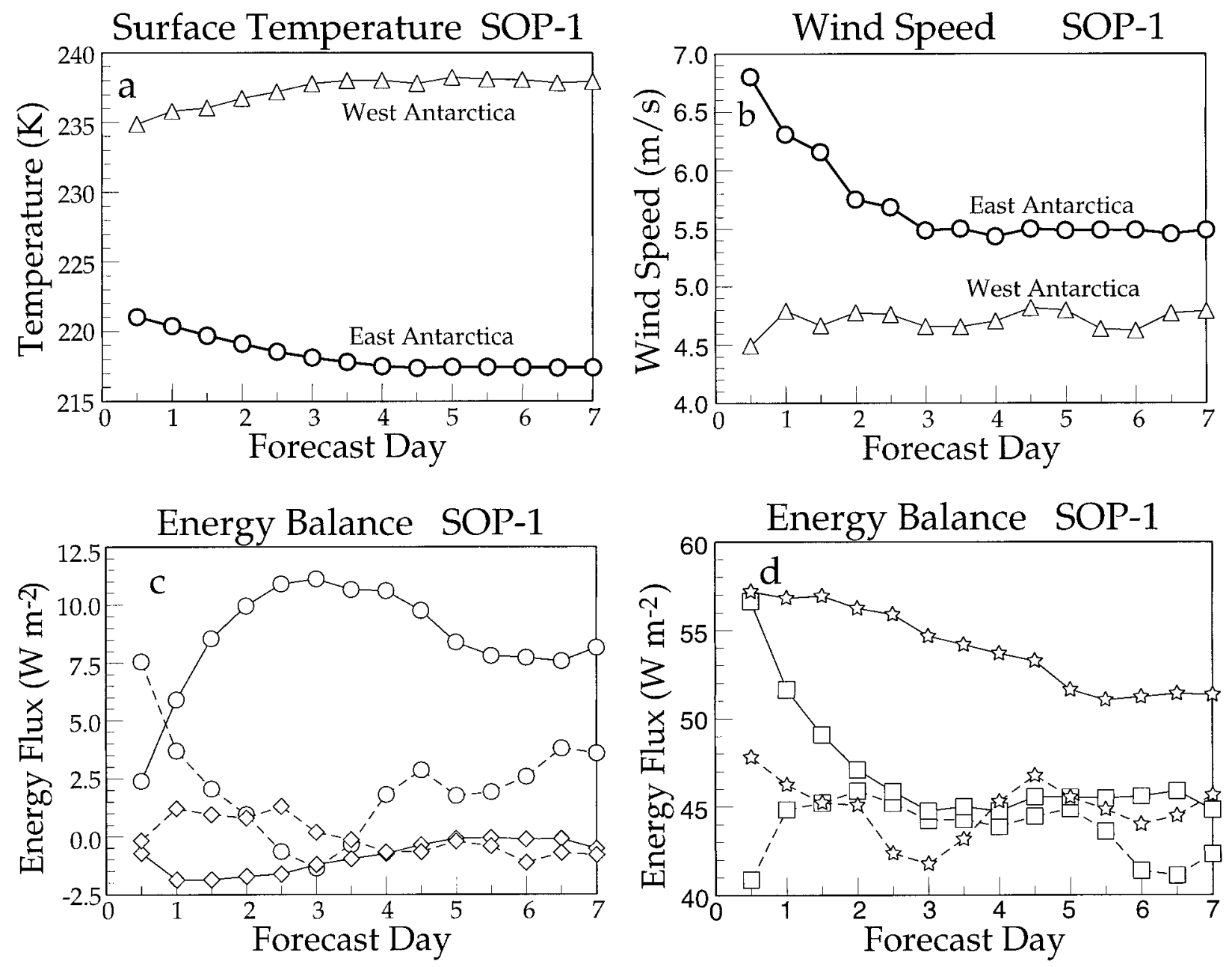

FIG. 3. Various area-averaged forecast fields vs forecast time for East and West Antarctica during SOP-1: (a) surface temperature (K), (b) wind speed $\left(\mathrm{m} \mathrm{s}^{-1}\right)$, (c) heat flux from the snowpack to the surface $\left(\mathrm{W} \mathrm{m}^{-2}\right.$, circles) and net energy balance at the surface (W $\mathrm{m}^{-2}$, diamonds), and (d) net longwave radiative energy loss at the surface ( $\mathrm{W} \mathrm{m}^{-2}$, stars) and surface warming by sensible heat flux (W $\mathrm{m}^{-2}$, squares). Thick (thin) lines in (a) and (b) and solid (dashed) lines in (c) and (d) represent East (West) Antarctic values.

At the same time, the slight increase in the difference, 2-m temperature minus surface temperature, for East Antarctica indicates increasing static stability. The increasing static stability over East Antarctica contributes to decreasing turbulent heat flux downward to the surface (King and Connolley 1997). Turbulent heat flux divergence, not radiative flux divergence, is the primary direct source of atmospheric cooling in the Antarctic winter boundary layer. The change with time of sensible heat flux and the 10-m wind speed are positively correlated for both East and West Antarctica (Figs. 3b and $3 d)$. The decrease with time of the katabatic winds over East Antarctica may appear unusual given the intensifying inversion; however, this emphasizes the subtle relationship between atmospheric temperature at model levels and the downslope pressure gradient force in the katabatic layer.

This difference in behavior between East and West Antarctica is shown by the net energy balance (Fig. 3c).
The balance of terms is generally negative, implying cooling, over East Antarctica during the forecast period. Despite the net balance of $-0.2 \mathrm{~W} \mathrm{~m}^{-2}$ for day 0.5 over West Antarctica, this quantity is positive from day 1.0 to day 3.0, implying regional warming. A positive feedback apparently contributes to the continued cooling over East Antarctica during the forecast period. The cooling surface increases the static stability, which decreases the contribution toward surface warming by turbulent heat flux. At the same time, upward longwave radiation and the net longwave cooling decrease. The longwave change, however, is unable to offset the reduction in turbulent warming at the surface. Consequently, the surface continues to cool. Over East Antarctica, Table 1 and Fig. 3 indicate that compensation for the reduced turbulent heating occurs from increased heat flux upward from the snowpack. Over West Antarctica, the balance is more easily achieved, and the flux from the snowpack decays initially, then remains relatively small. 
Energy Balance for SOP-1

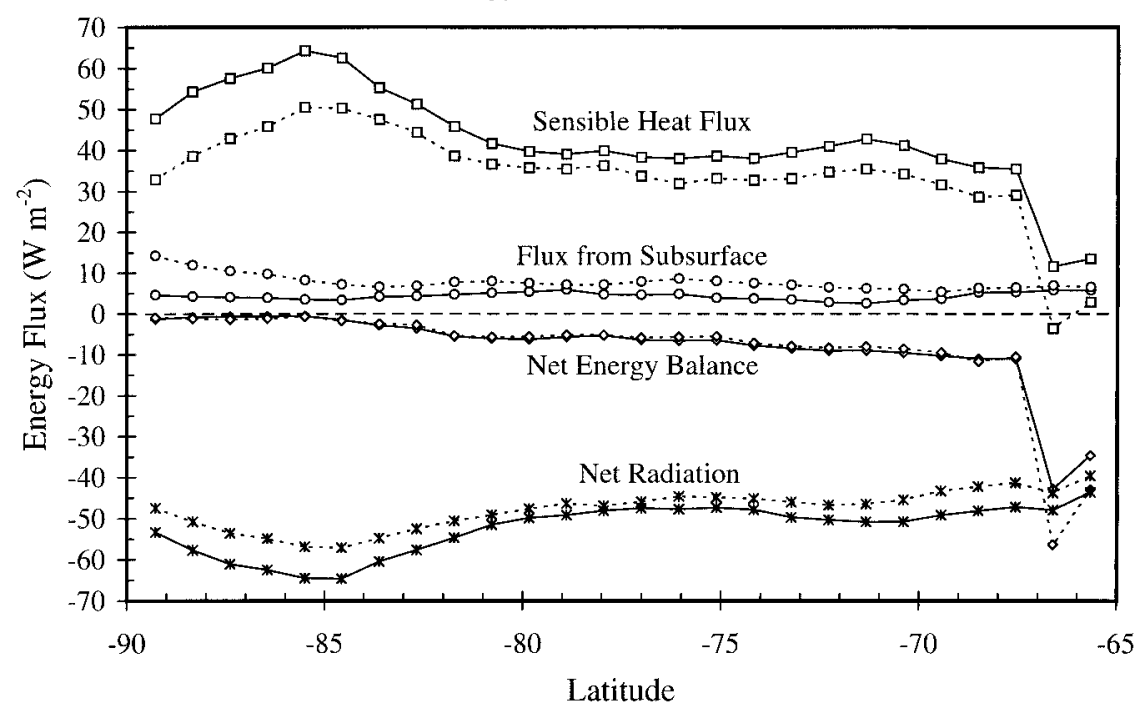

FIG. 4. Plot of NCEP MRF forecast surface energy balance terms $\left(\mathrm{W} \mathrm{m}^{-2}\right)$ vs latitude during FROST SOP-1 including sensible heat flux (squares), net radiation (asterisks), flux from the subsurface (circles), and the net energy balance (diamonds). Solid (dashed) lines represent the 0.5 day ( 7.0 day) forecast.

The latitudinal distribution from $90^{\circ}$ to $65^{\circ} \mathrm{S}$ of the surface energy balance terms is displayed in Fig. 4. Latent heat flux is not plotted in the figure as this term is of much smaller magnitude than other terms. As was seen previously, the main balance is between the cooling by net radiation and warming by downward sensible heat flux. Both tend to decrease slightly in magnitude from forecast day 0.5 to forecast day 7.0. The maximum in sensible heat flux near $85^{\circ} \mathrm{S}$ results from high winds near the Transantarctic Mountains. The magnitude of the sensible heat flux decreases with time faster than that of the net radiation, consequently the heat flux up from the snowpack must increase to maintain the energy balance. Between the South Pole and $68^{\circ} \mathrm{S}$, the net balance changes very slightly between day 0.5 and day 7.0. North of $68^{\circ} \mathrm{S}$, open water is present and the net balance is large and negative.

An evaluation of model surface energy balance over Antarctica has recently been carried out by King and Connolley (1997) for the Unified Climate Model of the U.K. Meteorological Office. They provide observations at several Antarctic stations for comparison against model output. Table 2 compares observational data compiled by King and Connolley for the South Pole station

TABLE 2. NCEP operational forecast surface energy balance near the South Pole for Jul 1994 (SOP-1). Values are in W $\mathrm{m}^{-2}$ unless otherwise noted.

\begin{tabular}{|c|c|c|c|c|c|}
\hline Source & $\begin{array}{l}\text { King and Connolley } \\
\text { multiyear Jul }\end{array}$ & $\begin{array}{l}\text { Forecast day } 0.5 \\
\text { Jul } 1994\end{array}$ & $\begin{array}{c}\text { Forecast day } 7.0 \\
\text { Jul } 1994\end{array}$ & $\begin{array}{l}\text { Reanalysis } \\
\text { Jul } 1994\end{array}$ & $\begin{array}{c}\text { Reanalysis } \\
\text { Jul 1982-94 }\end{array}$ \\
\hline Location & Observations $-90^{\circ} \mathrm{S}$ & $-89.2766^{\circ} \mathrm{S}$ & $-89.2766^{\circ} \mathrm{S}$ & -88.5420 & $-88.5420^{\circ} \mathrm{S}$ \\
\hline Longwave up & -117 & -118.5 & -106.6 & -107.3 & -113.3 \\
\hline Longwave down & +103.4 & +65.2 & +59.2 & +41.7 & +52.0 \\
\hline Net longwave & -14 & -53.3 & -47.5 & -65.7 & -61.3 \\
\hline Shortwave up & 0 & 0 & 0 & 0 & 0 \\
\hline Shortwave down & 0 & 0 & 0 & 0 & 0 \\
\hline Net shortwave & 0 & 0 & 0 & 0 & 0 \\
\hline Net radiation & -14 & -53.3 & -47.5 & -65.7 & -61.3 \\
\hline Sensible heat & - & +47.8 & +32.9 & +65.0 & +60.4 \\
\hline Latent heat & - & -0.3 & -0.5 & -4.4 & -3.7 \\
\hline Sensible + latent & +11 & +47.5 & +32.4 & +60.6 & +56.7 \\
\hline Flux from snowpack & +2.4 & +4.6 & +14.2 & 0.0 & 0.0 \\
\hline Net balance & - & -1.3 & -0.9 & -5.1 & -4.7 \\
\hline Albedo & - & - & - & - & - \\
\hline Surface temp $\left({ }^{\circ} \mathrm{C}\right)$ & - & -59.5 & -65.4 & -64.9 & -62.7 \\
\hline $1.5-\mathrm{m}$ temp $\left({ }^{\circ} \mathrm{C}\right)$ & -60.6 & - & - & - & - \\
\hline 2 -m temp $\left({ }^{\circ} \mathrm{C}\right)$ & - & -58.0 & -63.2 & -63.1 & -60.8 \\
\hline Medium cloud (\%) & - & 11.9 & 9.0 & 7.1 & 11.7 \\
\hline
\end{tabular}


against the MRF output zonally averaged at $89.28^{\circ} \mathrm{S}$. Their values are climatological averages for July, while the model output is for SOP-1 during July 1994. Consequently, some difference between model results and observations will result from interannual variability. Comparison of the surface and 2-m temperatures for the model against the observed $1.5-\mathrm{m}$ temperature demonstrates the finding of BCG that the near-surface temperatures in the model are warmer than the observed values early in the forecast. By day 7.0, model temperatures are colder than the observed climatological temperature at $1.5 \mathrm{~m}$. The forecast $2-\mathrm{m}$ temperature at this time, however, is close to the AWS observed value of $-63.5^{\circ} \mathrm{C}$ at $3 \mathrm{~m}$ for July 1994 (Keller et al. 1996).

The upward longwave radiation decreases with time, yet compares reasonably well with the observations. The downward longwave radiation, however, is about $40 \mathrm{~W}$ $\mathrm{m}^{-2}$ too small. The deficit in downward longwave radiation is a common problem for modeling studies, particularly for Antarctica (King and Connolley 1997; Briegleb and Bromwich 1998). The MRF may have a global tendency toward the underprediction of cloudiness and drying of the atmosphere (Betts et al. 1996; Cullather et al. 1997b). Both of these tendencies can exacerbate the downward longwave deficit. This results in the magnitude of the MRF net longwave radiation at the surface being about $35 \mathrm{~W} \mathrm{~m}^{-2}$ larger than observed.

King and Connolley (1997) combined observed latent and sensible heat fluxes and did not provide individual values for the two terms. Nevertheless, during the polar night, latent heat flux should be at least an order of magnitude smaller than the sensible heat flux (Stearns and Weidner 1993). For the MRF during SOP-1, sensible heat flux is two orders of magnitude larger than the latent heat flux and $21-37 \mathrm{~W} \mathrm{~m}^{-2}$ larger than the combined sensible and latent heat flux reported by King and Connolley (1997). Dalrymple et al. (1966) estimate the downward sensible heat flux to be $27.4 \mathrm{~W} \mathrm{~m}^{-2}$ for July 1958. An improved estimate made by Stearns and Weidner (1993) with AWS data arrived at a much lower value, $8.2 \mathrm{~W} \mathrm{~m}^{-2}$, for July 1986 . Their work indicates that sensible heat flux is highly sensitive to the wind at $3 \mathrm{~m}$ above ground level for strong inversions. King and Connolley (1997) found that the Unified Climate Model overestimates the surface fluxes in highly stable boundary layers due to an overly large magnitude of the stability function for the bulk transfer coefficients. A similar effect could also be occurring within the MRF. Furthermore, the weakness of the MRF inversion noted by BCG implies an underestimated static stability and, ultimately, overestimated surface fluxes. Additionally, the vertical resolution of the MRF may not allow the model to capture the most intense layer of the inversion, normally close to the surface. The latent heat flux values in Table 2 can be compared with estimates of $-0.5 \mathrm{~W}$ $\mathrm{m}^{-2}$ by Dalrymple et al. (1966) and $-0.1 \mathrm{~W} \mathrm{~m}^{-2}$ by Stearns and Weidner (1993). A latent heat flux of $1 \mathrm{~W}$ $\mathrm{m}^{-2}$ is equivalent to an evaporation rate of $0.928 \mathrm{~mm}$ month $^{-1}$.

The surface cooling during the forecast period also results in the heat flux from the snowpack increasing from $4.6 \mathrm{~W} \mathrm{~m}^{-2}$ at day 0.5 to $14.2 \mathrm{~W} \mathrm{~m}^{-2}$ at day 7.0. The Antarctic snowpack does not conduct heat well and should not contribute much to the time-averaged energy balance during the seasonally stable month of July. Thus the MRF flux from the snowpack is 2-6 times too large in Table 2. Dalrymple et al. (1966) estimate the observed flux at $1.4 \mathrm{~W} \mathrm{~m}^{-2}$. The high value for the MRF may indicate that subsurface temperatures are too warm and not properly adjusting to the model climate. The snowpack heat flux does help balance the excessive longwave cooling at the surface. Similar evaluations at other Antarctic stations (not shown) also show marked excesses in longwave cooling, sensible heat flux, and snowpack heat flux.

An interesting feature seen in Fig. 4 is that the zonally averaged net surface energy balance is negative by up to $10 \mathrm{~W} \mathrm{~m}^{-2}$ at latitudes entirely over the Antarctic ice sheet, permanent ice shelves, or sea ice. This imbalance is significant and apparently results from sea ice treatment in the model. Figure 5 displays the net surface energy balance south of $70^{\circ} \mathrm{S}$. Notice that over the Ross $\left(150^{\circ} \mathrm{W}-165^{\circ} \mathrm{E}\right)$ and Ronne-Filchner $\left(40^{\circ}-70^{\circ} \mathrm{W}\right)$ Ice Shelves and the surrounding sea ice zone the balance is negative by roughly $20 \mathrm{~W} \mathrm{~m}^{-2}$. Despite the negative net balance, the temperature rises over the Ronne-Filchner Ice Shelf and the nearby Weddell Sea (Fig. 2). This unrealistic behavior can result from the physically inconsistent boundary conditions for the computation of surface temperature over sea ice. A simple improvement to the surface energy balance would be to treat the ice shelves as part of the Antarctic continent.

\section{Operational forecasts for SOP-2 and SOP-3}

In the previous section, the surface energy balance was evaluated in the absence of significant shortwave radiation. In this section, we examine the balance during the austral spring and summer when surface heating by solar radiation counters the cooling by longwave radiation. Figure 6 displays the surface temperature over high southern latitudes during SOP-2. Interior temperatures are about $20 \mathrm{~K}$ warmer than during SOP-1. The forecast drift from day 0.5 to day 7.0 is somewhat less than that of SOP-1; however, temperature still generally increases over West Antarctica and decreases over East Antarctica (Fig. 6b).

The time evolution of the surface energy balance for the polar cap south of $85^{\circ} \mathrm{S}$ is shown in Fig. 7. The surface energy balance over interior Antarctica appears to be more stable for the spring SOP than for the winter SOP. Correspondingly, the variation of the polar cap surface temperature is within about $1 \mathrm{~K}$ during the forecast period (not shown). The main balance is between heating by sensible heat flux down from the atmosphere 


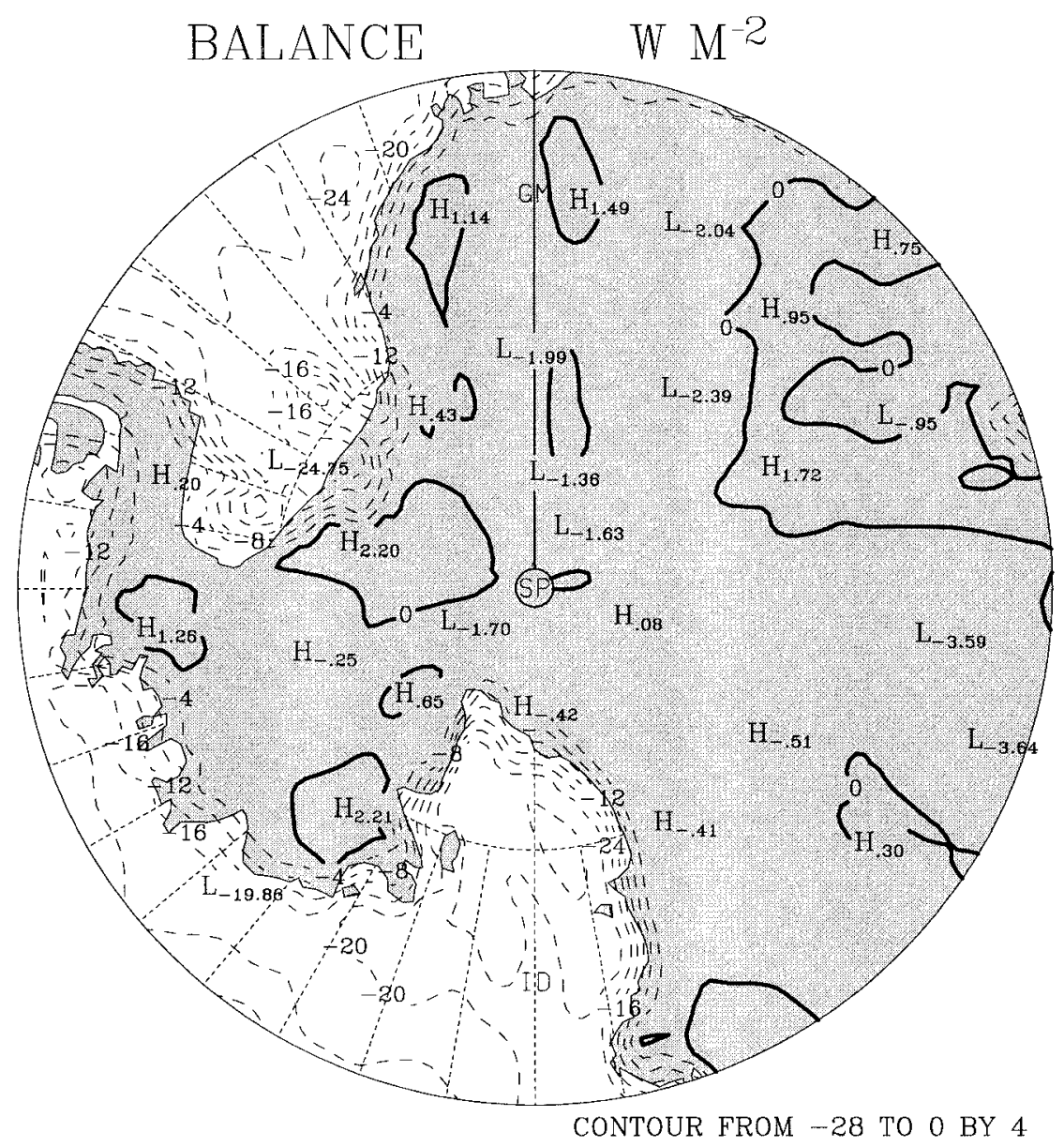

FIG. 5. Plot of the NCEP MRF forecast for day 0.5 of the net surface energy balance (W $\mathrm{m}^{-2}$ ). Contour interval is $4 \mathrm{~W} \mathrm{~m}^{-2}$. Thick contour is 0 .

and cooling by downward flux away from the surface into the snowpack. A modest decrease in sensible heat flux during the first 1.5 days of the forecast is largely balanced by a slight increase in the net radiation. This is accompanied by a slight decrease in area-averaged $10-\mathrm{m}$ wind speed from $6.1 \mathrm{~m} \mathrm{~s}^{-1}$ at day 0.5 to $5.4 \mathrm{~m}$ $\mathrm{s}^{-1}$ at day 7.0. Interestingly, the net radiation is close to zero after day 1.5. The MRF apparently models the spring Antarctic warming as primarily due to atmospheric heat fluxes. While the net surface energy balance in Fig. 7 is typically small and positive, there is a slight diurnal variation, perhaps due to terrain asymmetry. This leads to a slight diurnal cycle of temperature with values oscillating about $0.4 \mathrm{~K}$ between the forecasts every $12 \mathrm{~h}$.

The energy balance terms for SOP-2 near the South Pole are compared against the climatological observations compiled by King and Connolley (1997) in Table 3 . Their values are averaged over October and November to approximately match the 15 October- 15 November period of SOP-2. Low-level model temperatures are 3-5 K warmer than the observed temperature with the difference decreasing over time. Downward longwave radiation by the MRF is again $20-30 \mathrm{~W} \mathrm{~m}^{-2}$ too small, leading to a large overestimate in the net longwave cooling at the surface. Interestingly, this error is largely balanced by excessive net shortwave radiation of almost $25 \mathrm{~W} \mathrm{~m}^{-2}$. The Antarctic atmosphere is too transparent as the downward shortwave radiation is $31-35 \mathrm{~W} \mathrm{~m}^{-2}$ too large. Betts et al. (1996) indicate that the excessive transparency could be a global problem. Insufficient cloudiness, also noticed by Betts et al. (1996) in their boundary layer study comparing MRF output with observations at Manhattan, Kansas, contributes to the excessive shortwave radiation and deficit in longwave radiation at the surface. The model cloudiness at midlevels near the South Pole, about 20\%, compares with climatological observations of about 50\% cloudiness for October-November (Schwerdtfeger 1970). Cloudiness for the MRF is much less at high levels and nonexistent at low levels near the South Pole, due to the elevated surface. Table 3 also suggests the MRF surface albedo should be increased by about 0.06 over the Antarctic ice sheet. Furthermore, the observations suggest that the model's sensible heat flux, which is directed downward at about $15 \mathrm{~W} \mathrm{~m}^{-2}$, should be directed upward with a 

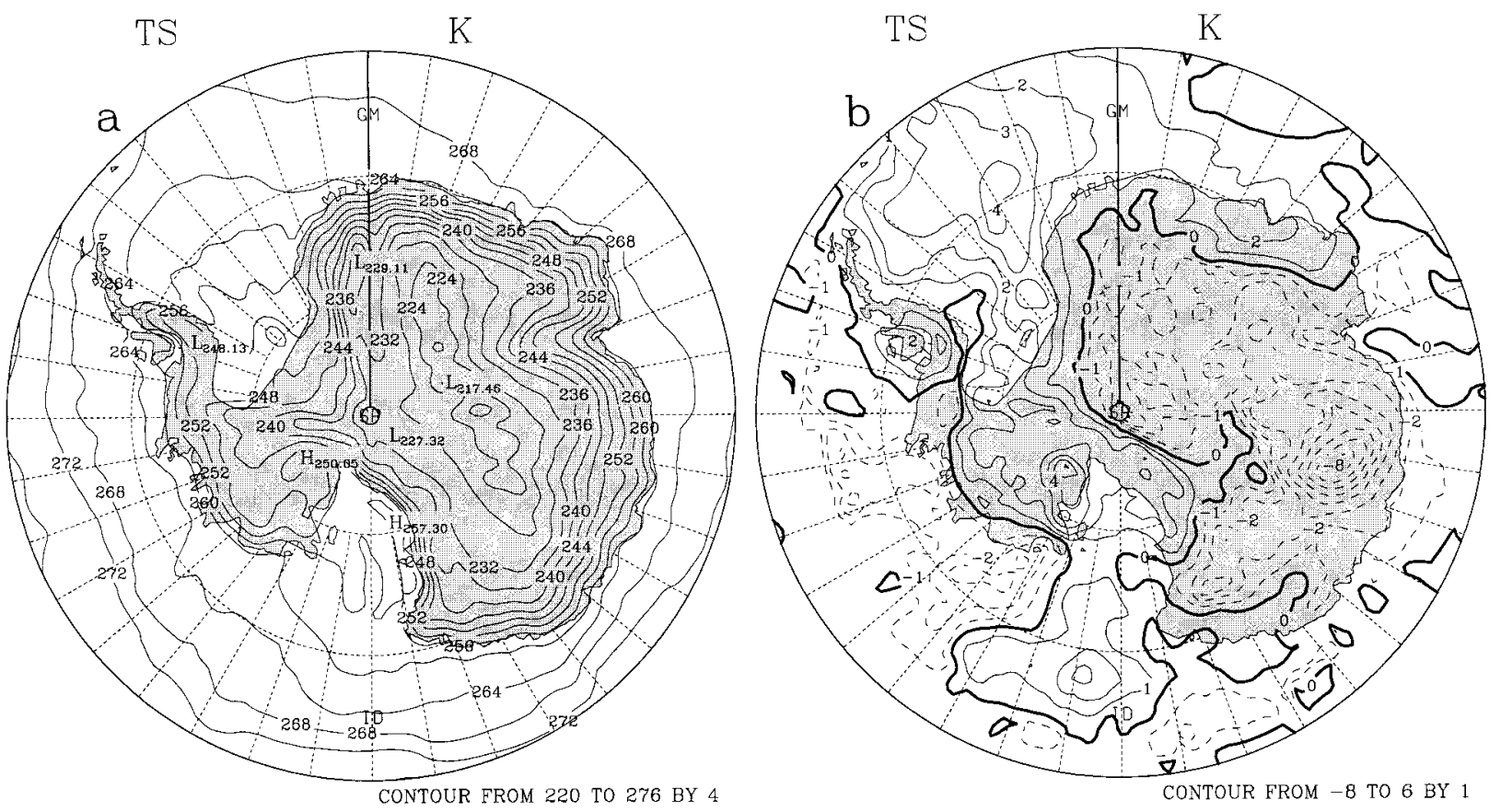

FIG. 6. As in Fig. 2 except for FROST SOP-2 (15 Oct-15 Nov 1994) for (a) day 0.5 and (b) the difference between day 7.0 and day 0.5 . Contour interval is $4 \mathrm{~K}$ in (a) and $1 \mathrm{~K}$ in (b).

magnitude of about $5 \mathrm{~W} \mathrm{~m}^{-2}$. The apparently spurious heating from the atmospheric turbulent flux resulted in excess heat flux into the snowpack, about $11-15 \mathrm{~W} \mathrm{~m}^{-2}$ more than that observed.

Figure 8 displays the latitudinal distribution of energy balance terms for SOP-2 at day 0.5 and day 6.5. As the latent heat flux and net energy balance were similar at these two times, only the day 0.5 values of these two fields are plotted. Both the sensible and subsurface flux-

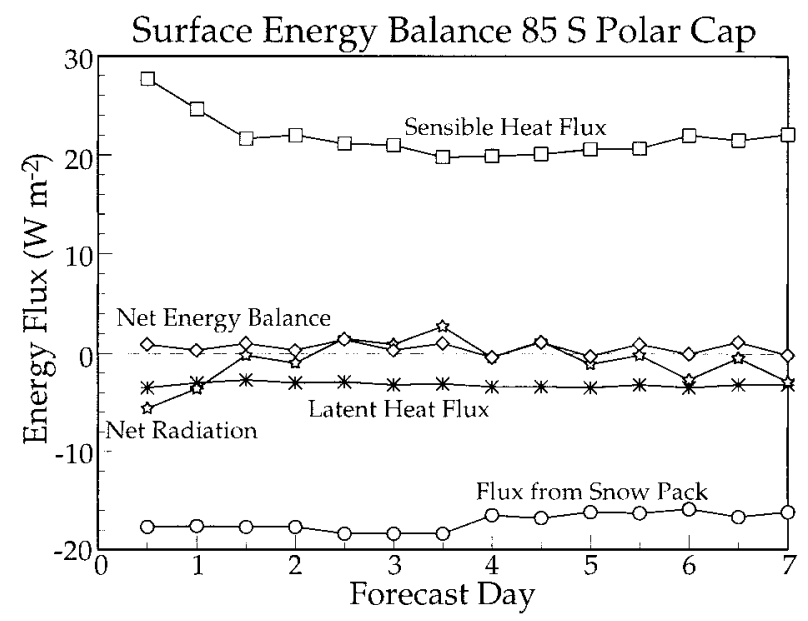

FIG. 7. Various forecast fields $\left(\mathrm{W} \mathrm{m}^{-2}\right)$ averaged poleward of $85^{\circ} \mathrm{S}$ vs forecast time for SOP-2 including net radiation at the surface (stars) and surface warming by downward sensible heat flux (squares), heat flux from the snowpack to the surface (circles), latent heat flux (asterisks), and net energy balance at the surface (diamonds). es are excessive as seen from Table 3. The influence of open water north of $73^{\circ} \mathrm{S}$ is very apparent for the latent heat flux and net radiation. The net balance is again negative between $85^{\circ}$ and $73^{\circ} \mathrm{S}$ due to the large negative balance over sea ice and ice shelves. The net radiation tends to increase toward more realistic values between day 0.5 and day 6.5 .

The summer SOP during January 1995 will not be evaluated in great detail as significant changes to the model were incorporated during this month, and there were problems with the initialization of model sea ice. Table 4 shows the average surface energy balance near the South Pole for the day 0.5 and day 7.0 forecasts for SOP-3. Due to the two different model regimes, caution must be used in interpreting the monthly average fields. Some trends seen in the spring SOP are also seen in SOP-3. Downward shortwave radiation, the magnitude of the net shortwave and longwave radiation, the heat flux into the snowpack and the lower boundary layer temperature are too large, and the downward longwave radiation and albedo are too small compared to the climatological observations. The net radiation at the surface for the MRF is surprisingly close to that of the observations, despite errors of over $40 \mathrm{~W} \mathrm{~m}^{-2}$ in the net shortwave and longwave radiation. During this month, sensible and latent heat flux are the same order of magnitude and the same sign. Both contribute modestly to cooling at the surface. Stearns and Weidner (1993) did not estimate latent heat flux based upon AWS observations for January; however, their December 1986 estimate of $23.4 \mathrm{~W} \mathrm{~m}^{-2}$ provides an approximation 
TABLE 3. NCEP operational forecast surface energy balance, 15 Oct-15 Nov 1994 (SOP-2). Values are in W m ${ }^{-2}$ unless otherwise noted.

\begin{tabular}{lcccc}
\hline \hline \multicolumn{1}{c}{ Source } & $\begin{array}{c}\text { King and Connolley } \\
\text { multiyear }\end{array}$ & Forecast day 0.5 & Forecast day 7.0 & Reanalysis \\
1994
\end{tabular}

for the January value. Thus the MRF magnitude of 5$6 \mathrm{~W} \mathrm{~m}^{-2}$ may be an underestimate.

The change in model formulation during SOP-3 provides an opportunity to observe the changing balance between the two regimes. Forecasts initialized the first 10 days of January are run with a version of the MRF highly similar to those used for SOP-1 and SOP-2. The version of the MRF used for the reanalysis is similar to the operational version first used for forecasts initialized on or after 11 January. Figure 9 shows the time evolution during January of forecast surface temperature, snowpack heat flux, sensible heat flux, and latent heat flux for the polar cap inside $85^{\circ} \mathrm{S}$. The scale on the

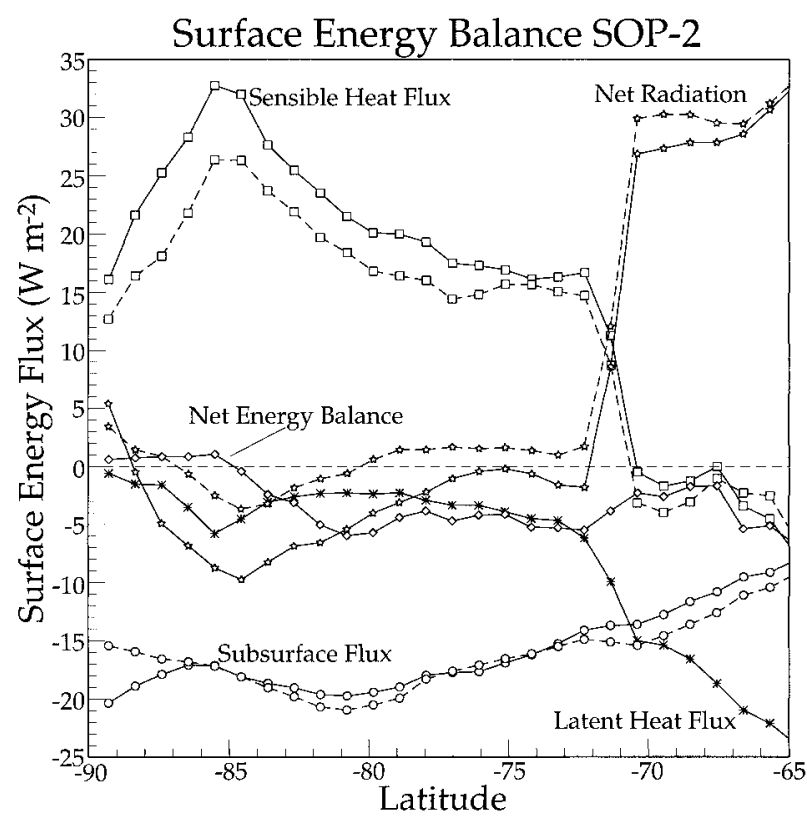

FIG. 8. As in Fig. 4 except for FROST SOP-2 with latent heat flux (asterisks). Dashed lines represent day 6.5. bottom of Fig. 9 shows the initialization date of the forecast. The day 0.5 forecast is valid at 1200 UTC of the same day, while the day 7.0 forecast is valid at 0000 UTC 7 days later. Significant and parallel jumps in the fields are seen at 11 January for both the day 0.5 and day 7.0 forecasts. This occurs despite the fact that the forecasts are valid 6.5 days apart. It is apparent that the updated forecast model predicts warmer surface temperature (Fig. 9a). This is particularly true for the day 7.0 forecast, which has a longer response time to the model changes. As solar radiation is decreasing during January, the surface temperature gradually resumes a basically downward trend later in the month. From Fig. $9 \mathrm{~b}$, it is seen that all the surface cooling due to heat flux into the snowpack occurred prior to the model change. Nevertheless, the monthly average values are too large in magnitude in Table 4.

The loss of the heat sink into the snowpack is the most likely cause of the surface warming at the transition. In order to maintain the surface energy balance, the sensible and latent heat fluxes contribute more to surface cooling for the updated version of the MRF. It is not clear whether the changes in sensible and latent heat flux are direct results of changes in their parameterizations, or whether they are simply responding to the increased surface temperature. Furthermore, since Table 4 indicates that the time-average model surface temperature was too warm for this month, the model update appears to have degraded the forecast of Antarctic surface temperature. The previously excessive heat flux between the surface and snowpack was overcorrected by the new regime.

\section{NCEP-NCAR reanalysis evaluation}

The FROST SOPs also provide an opportunity to evaluate the NCEP-NCAR reanalysis for high southern 
TABLE 4. NCEP operational forecast surface energy balance near the South Pole during Jan 1995 (SOP-3). Values are in W m ${ }^{-2}$ unless otherwise noted.

\begin{tabular}{|c|c|c|c|c|}
\hline Source & $\begin{array}{l}\text { King and Connolley } \\
\text { multiyear Jan }\end{array}$ & $\begin{array}{l}\text { Forecast day } 0.5 \\
\quad \text { Jan } 1995\end{array}$ & $\begin{array}{l}\text { Forecast day } 7.0 \\
\text { Jan } 1995\end{array}$ & $\begin{array}{c}\text { Reanalysis } \\
\text { Jan } 1995\end{array}$ \\
\hline Location & Observations $-90^{\circ} \mathrm{S}$ & $-89.2766^{\circ} \mathrm{S}$ & $-89.2766^{\circ} \mathrm{S}$ & $-88.5420^{\circ} \mathrm{S}$ \\
\hline Longwave up & -216.1 & -216.15 & -225.6 & -219.6 \\
\hline Longwave down & +165 & +124.2 & +127.1 & +117.0 \\
\hline Net longwave & -51 & -91.9 & -98.5 & -102.6 \\
\hline Shortwave up & -295.5 & -331.8 & -334.7 & -339.0 \\
\hline Shortwave down & +364.8 & +442.4 & +447.3 & +452.6 \\
\hline Net shortwave & +69.3 & +110.6 & +112.6 & +113.6 \\
\hline Net radiation & +18 & +18.7 & +14.1 & +10.9 \\
\hline Sensible heat & - & -8.0 & -1.2 & -5.5 \\
\hline Latent heat & - & -6.0 & -5.4 & -6.2 \\
\hline Sensible + latent & -14 & -14.0 & -6.6 & -11.7 \\
\hline Flux from snowpack & -3.8 & -5.0 & -8.6 & 0.0 \\
\hline Net balance & - & -3.0 & -1.0 & -0.7 \\
\hline Albedo & 0.81 & 0.75 & 0.75 & 0.75 \\
\hline Surface temp $\left({ }^{\circ} \mathrm{C}\right)$ & - & -24.4 & -22.2 & -23.8 \\
\hline 1.5-m temp $\left({ }^{\circ} \mathrm{C}\right)$ & -27.6 & - & - & - \\
\hline 2-m temp $\left({ }^{\circ} \mathrm{C}\right)$ & - & -24.7 & -22.3 & -23.9 \\
\hline Medium cloud (\%) & - & - & - & 19.8 \\
\hline
\end{tabular}
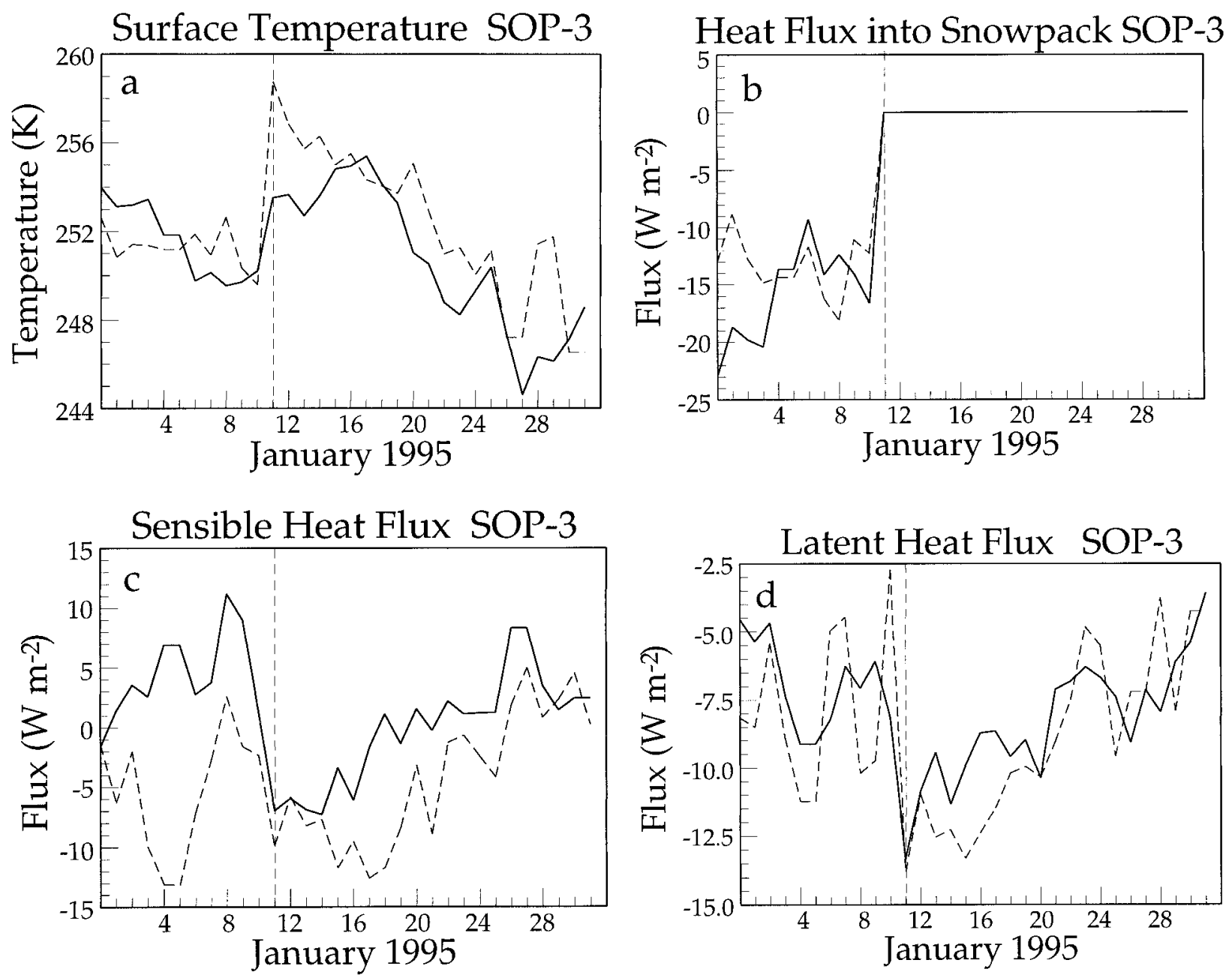

FIG. 9. Forecast fields averaged poleward of $85^{\circ} \mathrm{S}$ plotted vs initialization date during FROST SOP-3: (a) surface temperature (K), (b) heat flux into snowpack ( $\left.\mathrm{W} \mathrm{m}^{-2}\right)$, (c) sensible heat flux $\left(\mathrm{W} \mathrm{m}^{-2}\right)$, and (d) latent heat flux ( $\left.\mathrm{W} \mathrm{m}^{-2}\right)$. Solid line is day 0.5 forecast, and dashed line is day 7.0 forecast. 


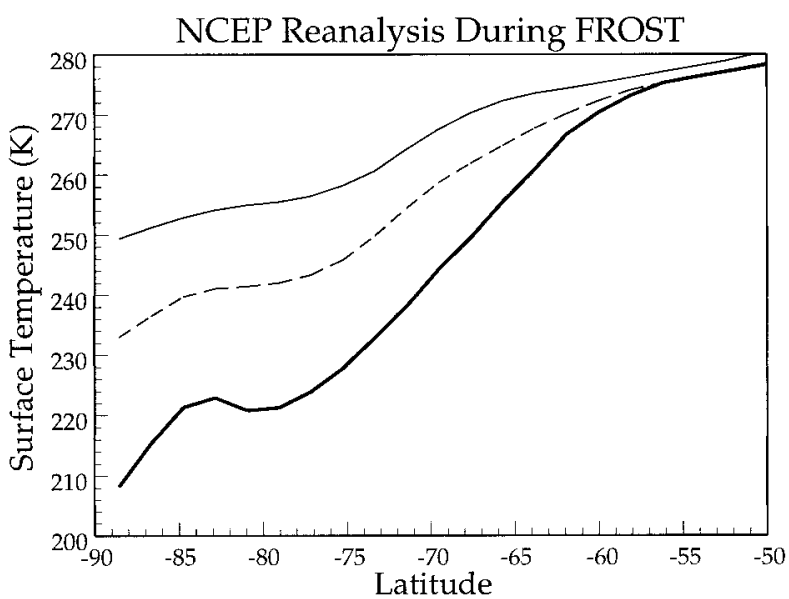

FIG. 10. Zonally averaged surface temperature (K) vs latitude for the NCEP-NCAR reanalysis during SOP-1 (thick solid line), SOP 2 (dashed line), and SOP-3 (thin solid line).

latitudes. Unlike the operational MRF, which is frequently updated, the NCEP model used for the reanalysis is frozen. Thus, while evaluations of the operational model can lose relevance with time as new parameterizations are implemented, evaluations for the reanalysis maintain their significance. Moreover, evaluations are especially important for the reanalysis as it is expected to have considerable use within the next few years. It is also an opportunity to compare the reanalysis against previous versions of the NCEP analysis-forecast system.

Figure 10 shows the zonally averaged surface temperature from the reanalysis for the three SOPs. It is apparent that the seasonal variation increases southward toward the South Pole. In this section, we will concentrate on zonally averaged fields for simplicity. Figure 11 shows surface energy balance terms plotted versus latitude for the winter SOP. Similar to Fig. 4 for the operational model, the main balance is between sensible heat flux and net longwave radiation over Antarctic latitudes. The balance terms for the grid latitude nearest the South Pole are shown in Table 2. Several components of the surface energy balance for the reanalysis are degraded compared to that of the operational forecasts for this period. The magnitude of the net longwave radiation has increased by $12-18 \mathrm{~W} \mathrm{~m}^{-2}$ compared to the operational forecasts. The downward sensible heat flux is also increased by $17-32 \mathrm{~W} \mathrm{~m}^{-2}$. By comparison with the 13-yr mean of the reanalysis from 1982 to 1994, it can be seen that the reanalysis for July 1994 is well representative of multiyear mean. Thus, we can use FROST SOP-1 as a good example of the Antarctic winter.

Table 2 also shows that the deficit of downward longwave radiation has increased from $38-44 \mathrm{~W} \mathrm{~m}^{-2}$ in the operational forecasts to $62 \mathrm{~W} \mathrm{~m}^{-2}$ in the reanalysis. The extremely small cloud fraction, $7.1 \%$ at middle levels, is contributing to the deficit in downward longwave ra-

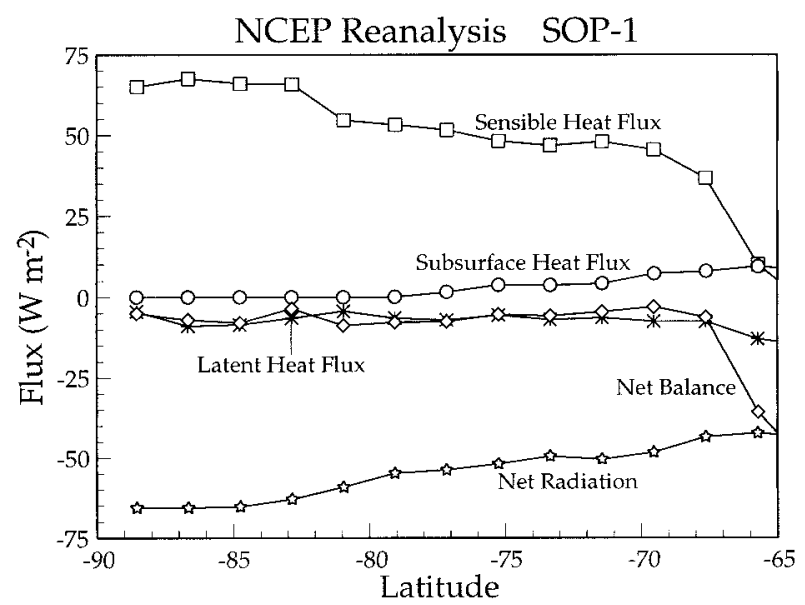

FIG. 11. Plot of NCEP reanalysis surface energy balance terms (W $\mathrm{m}^{-2}$ ) vs latitude during Jul 1994 including sensible heat flux (squares), net radiation (stars), flux from the subsurface (circles), latent heat flux (asterisks), and the net energy balance (diamonds).

diation. The deficit is somewhat smaller and the midlevel cloudiness increased for the 13-yr mean. Furthermore, the change made in the operational forecast model during January 1995 (Fig. 9) has resulted in no heat flux through the Antarctic snowpack. This is probably an improvement during winter over the previous operational forecasts, which included an excessive heat flux upward through the snowpack, especially several days into the forecast period. The loss of the flux up from the snowpack, however, is apparently contributing to lower boundary layer temperatures about $3^{\circ} \mathrm{C}$ colder than the observed climatology.

Curiously, the surface energy terms are not in balance as the net balance shows a deficit of $5.1 \mathrm{~W} \mathrm{~m}^{-2}$ for SOP-1. The excessive latent heat flux accounts for $87 \%$ of the imbalance. The large latent heat flux appears to be related to the excessive surface fluxes for stable nighttime boundary layers reported by Betts et al. (1996) in a study comparing MRF fluxes against observations for Manhattan, Kansas. Using essentially the same version of the NCEP model, they found very large latent heat flux directed upward and sensible heat flux directed downward for high wind speed at night. Betts et al. attributed the excessive fluxes to overly large drag coefficients for highly stable boundary layers.

The reanalysis forecasts, available every 5 days starting July 5 for SOP-1, are checked to see if the surface energy deficit in Table 2 was consistent with the evolution of surface temperature. It is found that the six 12-h forecasts have average surface temperatures of $-69.1^{\circ} \mathrm{C}$ at $88.54^{\circ} \mathrm{S}$. This is $4.2^{\circ} \mathrm{C}$ colder than the monthly average for the reanalysis. Thus the surface temperature evolution appears to be consistent with the net energy balance in Table 2. Figure 11 shows that the plotted balance terms vary little over Antarctic latitudes. The negative surface net balance is very close to the magnitude of the excessive latent heat flux. The heat 


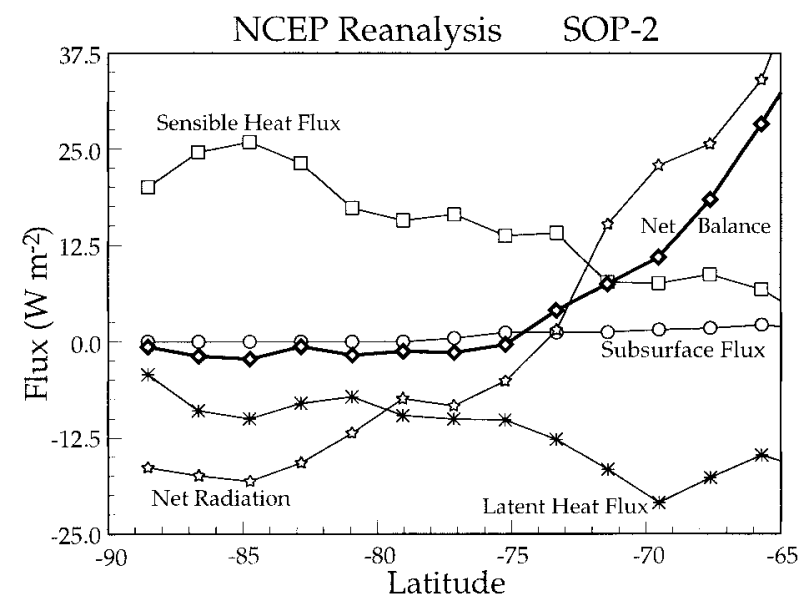

FIG. 12. As in Fig. 11 except for the average of Oct and Nov 1994.

flux up from the subsurface is zero over the Antarctic ice sheet and has a value of a few watts per square meter over latitudes with ice shelves and sea ice. The net balance becomes strongly negative over open water, which is present north of $68^{\circ} \mathrm{S}$.

For SOP-2 during austral spring, energy balance terms are plotted between $65^{\circ} \mathrm{S}$ and the South Pole in Fig. 12 , and the balance at $88.54^{\circ} \mathrm{S}$ is shown in Table 3. An important difference between the operational forecasts and the reanalysis is that net radiation is within about $5 \mathrm{~W} \mathrm{~m}^{-2}$ of the climatologically observed values for the operational forecasts and it is has a deficit of about $25 \mathrm{~W} \mathrm{~m}^{-2}$ for the reanalysis. This results from the net longwave radiational cooling, which is about 50 $\mathrm{W} \mathrm{m}{ }^{-2}$ too large. The excessive net shortwave radiation is unable to compensate for the longwave radiation. Again, the deficit in cloudiness contributes to the longwave and shortwave errors. It is interesting that the net surface energy balance is negative south of $75^{\circ} \mathrm{S}$ during this time of seasonal warming. Despite the negative balance, the lower boundary temperatures are about $7^{\circ} \mathrm{C}$ warmer than the climatological observations near the South Pole. A realistic seasonal heat flux into the snowpack could help provide a drag on the seasonal change and reduce the surface temperature. The relatively warm surface temperature in the reanalysis is apparently enhanced by the downward sensible heat flux. The observations suggest that sensible heat flux is of opposite sign and should contribute to cooling of the surface. In summary, the energy balance forecast by the operational model appears to be more realistic than that in the reanalysis during spring 1994.

The energy balance for the summer SOP is shown by Fig. 13 and Table 4. The reanalysis sensible heat flux is of relatively small magnitude over Antarctic latitudes for January. Consequently, cooling by the latent heat flux must contribute to balancing the positive net radiation. Stearns and Weidner (1993) did not provide an estimate of latent heat flux at the South Pole for January;

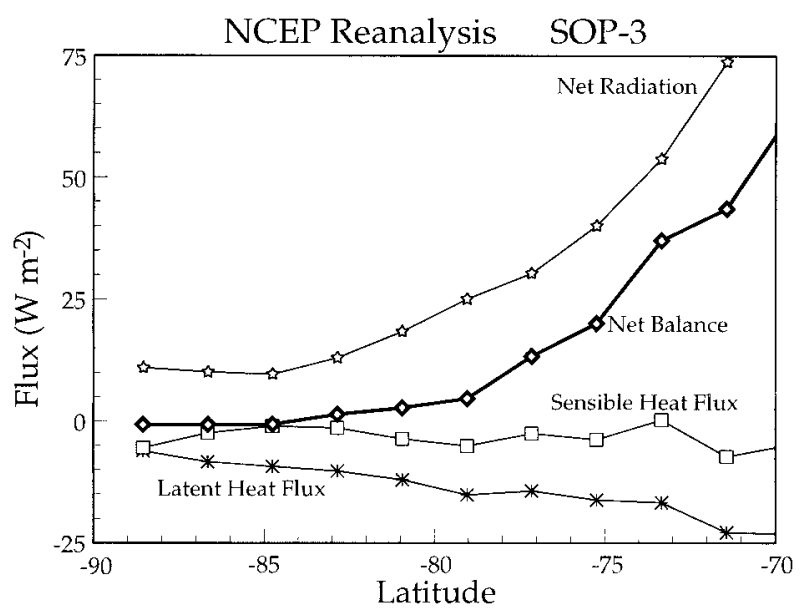

FIG. 13. As in Fig. 11 except for Jan 1995.

however, their estimate for December, $23.4 \mathrm{~W} \mathrm{~m}^{-2}$, suggests that the reanalysis value of $6.2 \mathrm{~W} \mathrm{~m}^{-2}$ is too small. This contrasts with the surprisingly large magnitude of latent heat flux during winter when the static stability was much larger. Again, significant deficits in the downward longwave radiation, cloudiness, and albedo impact the radiation. The shortwave and longwave errors tend to cancel, resulting in the net radiation being about 7 $\mathrm{W} \mathrm{m}{ }^{-2}$ too low near the South Pole. The nonexistent heat flux between the surface and snowpack probably contributes to the lower boundary layer temperature being about $4^{\circ} \mathrm{C}$ warmer than the observed climatological mean. A comparison of the surface energy balances for the operational forecasts and reanalysis for SOP-3 in Table 4 shows significantly more similarity than is seen for SOP-1 and SOP-2. Differences for SOP-3 include a smaller net radiation and no heat flux into the snowpack for the reanalysis.

From Fig. 13, it is apparent that the net surface energy balance during SOP-3 becomes increasingly positive north of about $85^{\circ} \mathrm{S}$. The zonal average of the net surface energy balance increases to the north due to large positive balances over open water. Between $85^{\circ}$ and $75^{\circ} \mathrm{S}$, however, the surface is almost all Antarctic ice sheet, permanent ice shelf, or sea ice. The horizontal distribution of the balance (not shown) indicates that the balance is near zero over the ice sheet, about $10-30 \mathrm{~W}$ $\mathrm{m}^{-2}$ over the Ross Ice Shelf, and even larger over the Ronne-Filchner Ice Shelf. The net radiation is correspondingly large over the permanent ice shelves. This accounts for the net radiation and net energy balance increasing to the north over these latitudes. Figure 14 shows the upward and downward fluxes of longwave and shortwave radiation. Net shortwave radiation is excessive over Antarctic latitudes, partly due to value of the surface albedo, about 0.75 . Observations suggest that the albedo is actually about 0.81 . The net shortwave radiation is fairly constant over Antarctic latitudes. Near the South Pole, net longwave cooling is also too large, 


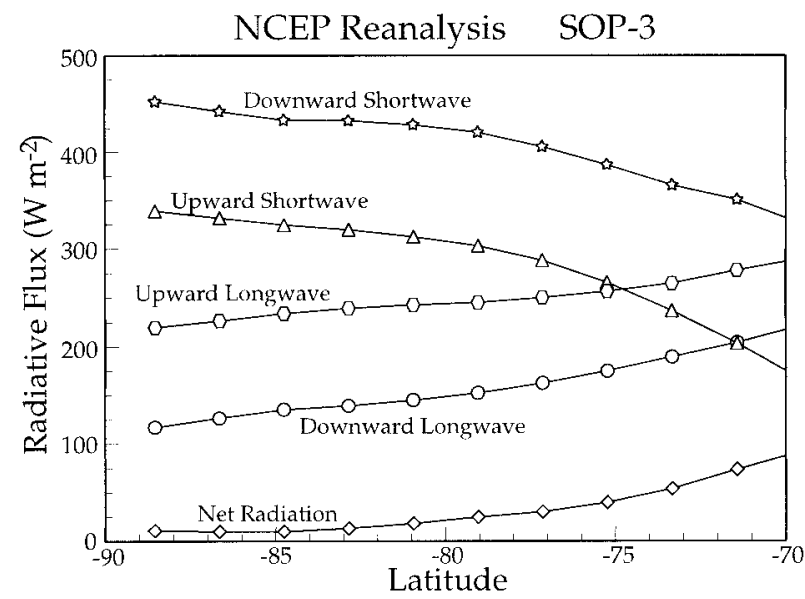

FIG. 14. As in Fig. 13 except for downward shortwave radiation (stars), upward shortwave radiation (triangles), upward longwave radiation (hexagons), downward longwave radiation (circles), and net radiation (diamonds).

thus compensating for the shortwave radiation. The downward longwave radiation increases more rapidly to the north than the upward longwave radiation. Therefore, net longwave cooling decreases and the net radiation increases to the north. The resulting positive summer balance over sea ice and ice shelves is consistent with the experience of the NCEP sea ice model forced by the MRF. A more realistic sea ice albedo (Grumbine 1994) was one of the changes incorporated in the January 1995 model update. In summary of the findings regarding the surface energy balance of the reanalysis, the balance is shown to be roughly equal to or degraded from that of operational forecasts during the three FROST SOPs.

\section{Conclusions}

The FROST study, including July 1994 (SOP-1), 15 October-15 November 1994 (SOP-2), and January 1995 (SOP-3) provides an ideal opportunity for evaluation of model forecasts of the surface energy budget in Antarctic latitudes. The present study examines the surface balance produced by the NCEP MRF for operational weather forecasts and the recent NCEP-NCAR reanalysis. Recurring features of the surface energy balance include excessive net longwave radiation, insufficient cloudiness in the middle troposphere, and excessive magnitude sensible heat flux. The longwave errors are largely the result of a persistent deficit in downward longwave radiation by about $30-50 \mathrm{~W} \mathrm{~m}^{-2}$. During the spring and summer SOPs, the excessive longwave cooling at the surface is primarily balanced by excessive solar shortwave heating resulting from the highly transparent atmosphere and the ice surface albedo near 0.75. Observations by King and Connolley (1997) suggest an albedo of 0.81 .

Seasonal characteristics of the surface energy balance include cooling over East Antarctica and slight warming over West Antarctica during NCEP forecasts for the winter SOP. The increasing static stability over East Antarctica apparently reduces the turbulent heat flux from the atmosphere and contributes to continued surface cooling. An approximate balance during winter forms between the excessive magnitudes of warming by downward sensible flux and surface cooling by longwave radiation. At the South Pole, wintertime surface warming by downward sensible heat flux is too large by about $21-37 \mathrm{~W} \mathrm{~m}^{-2}$ for the operational forecasts and $46-50 \mathrm{~W} \mathrm{~m}^{-2}$ for the reanalysis. In the operational forecasts, excessive heat flux up from the snowpack also helps to balance the longwave cooling during the winter SOP. For the operational forecasts during the spring SOP, sensible heat flux produces an excessive heating contribution by about $20 \mathrm{~W} \mathrm{~m}^{-2}$. This results in warmer than observed low-level atmospheric temperatures and excessive heat flux into the snowpack. A significant change in the energy balance results from an extensive model update beginning with the operational forecasts initialized on 11 January 1995 during the summer SOP. The update results in a significant increase in surface temperature, possibly due to the loss of cooling by heat flux into the snowpack. The updated model formulation is also used for the reanalysis.

The energy balance over Antarctica in the reanalysis is, in general, degraded from that of the operational forecasts for the winter and spring SOPs and roughly equivalent for the summer SOP. Latent heat flux during spring and especially winter is too large in the reanalysis for the cold Antarctic environment. During winter, the latent heat flux for the reanalysis is at least an order of magnitude larger than the generally very small observed values. This is apparently the result of a bias for nighttime stable boundary layers with high wind speed that was discussed by Betts et al. (1996). Sensible heat flux is excessive in magnitude and tends to heat the surface during the polar night for both the analysis and the operational forecasts.

The NCEP forecasts for Antarctic latitudes could be made more realistic in terms of the surface energy balance with several modifications. The surface albedo can be increased, and the diagnostic cloud prediction scheme or the moisture budget processes can be modified to produce more realistic Antarctic fields. The sensible and latent heat fluxes can be reduced toward the observed values by using parameterizations appropriate for extremely stable boundary layers. The heat flux through the Antarctic ice sheet and permanent ice shelves can be better treated. Another suggested improvement is to treat the permanent ice shelves as part of the Antarctic continent rather than as sea ice. A fundamental modeling problem that may be more difficult to solve, yet is highly significant to the surface energy balance, is the deficit in downward longwave radiation. Improvements to the NCEP MRF forecasts are regularly 
implemented. Nevertheless, all these suggestions are still relevant as of the final revision date of this paper.

Acknowledgments. This research was sponsored by the NSF/NCEP Joint Program in Numerical Weather Prediction via National Science Foundation Grant ATM9422104. The computations were performed with the assistance of the CRAY Y-MP of the Ohio Supercomputer Center. The authors thank John King, British Antarctic Survey, for providing observational data.

\section{REFERENCES}

Augustine, N. R., and Coauthors, 1997: The United States in Antarctica: Report of the U.S. Antarctic Program External Panel. National Science Foundation, Washington, DC, 94 pp. [Available from National Science Foundation, Arlington, VA 22230.]

Betts, A. K., S.-Y. Hong, and H.-L. Pan, 1996: Comparison of NCEPNCAR reanalysis with 1987 FIFE data. Mon. Wea. Rev., 124, $1480-1498$.

Bourke, W. P., 1996: Review of the performance of the Bureau of Meteorology Global Assimilation and Prediction system (GASP). Research Report on 1994 Modelling Workshop, BMRC Research Rep. 52, 47 pp. [Available from Bureau of Meteorology Research Centre, GPO Box 1289K, Melbourne, Victoria 3001, Australia.]

Briegleb, B. P., and D. H. Bromwich, 1998: Polar radiation budgets of the NCAR CCM3. J. Climate, 11, 1246-1269.

Bromwich, D. H., and S. R. Smith, Eds., 1993: U.S. FROST: Data and science plan. Report from the U.S. FROST Workshop, BPRC Rep. 7, 40 pp. [Available from Byrd Polar Research Center, Ohio State University, Columbus, OH 43210.]

_ - R. I. Cullather, and R. W. Grumbine, 1999: An assessment of the NCEP operational global spectral model forecasts and analyses for Antarctica during FROST. Wea. Forecasting, 14, 835850.

Campana, K. A., Y.-T. Hou, K. E. Mitchell, S.-K. Yang, and R. Cullather, 1994: Improved diagnostic cloud parameterization in NMC's global model. Preprints, 10th Conf. on Numerical Weather Prediction, Portland, OR, Amer. Meteor. Soc., 324-325.

Caplan, P., J. Derber, W. Gemmill, S.-Y. Hong, H.-L. Pan, and D. Parrish, 1997: Changes to the 1995 NCEP operational mediumrange forecast model analysis-forecast system. Wea. Forecasting, 12, 581-594.

Cullather, R. I., D. H. Bromwich, and R. W. Grumbine, 1997a: Validation of operational numerical analyses in Antarctic latitudes. J. Geophys. Res., 102, 13 761-13 784 .

—- Harshvardhan, and K. A. Campana, 1997b: Climatology of cloud and radiation fields in a numerical weather prediction model. Theor. Appl. Climatol., 57, 11-33.

Dalrymple, P. C., H. H. Lettau, and S. H. Wollaston, 1966: South Pole microphysical program: Data analysis. Studies in Antarctic Meteorology, M. J. Rubin, Ed., Antarctic Research Ser., Vol. 9, Amer. Geophys. Union, 13-57.

Dolgin, I. M., 1986: Climate of Antarctica. Oxonian Press Pvt. Ltd., 213 pp.

Drewry, D. J., 1983: The surface of the Antarctic ice sheet. Antarctica: Glaciological and Geophysical Folio, Scott Polar Research Institute, Cambridge, United Kingdom, Sheet 2.

Grumbine, R. W., 1994: A sea-ice albedo experiment with the NMC Medium Range Forecast Model. Wea. Forecasting, 9, 453-456.

Hanel, R. A., B. J. Conrath, V. G. Kunde, C. Prabhakara, I. Revah, V. V. Salomonson, and G. Wolford, 1972: The Nimbus 4 infrared spectroscopy experiment, I. calibrated thermal emission spectra. J. Geophys. Res., 77, 2629-2641.

Hong, S.-Y., and H.-L. Pan, 1996: Nonlocal boundary layer vertical diffusion in a medium-range forecast model. Mon. Wea. Rev., 124, 2322-2339.

Kalnay, E., and Coauthors, 1993: The NMC/NCAR CDAS/Reanalysis
Project. NMC Office Note 401, 42 pp. [Available from NOAA/ NCEP, 5200 Auth Rd., Washington, DC 20233.]

- , and Coauthors, 1996: The NCEP/NCAR 40-Year Reanalysis Project. Bull. Amer. Meteor. Soc., 77, 437-471.

Kanamitsu, M., 1989: Description of the NMC global data assimilation and forecast system. Wea. Forecasting, 4, 335-342.

—- and Coauthors, 1991: Recent changes implemented into the global forecast system at NMC. Wea. Forecasting, 6, 425-435.

Keller, L. M., G. A. Weidner, C. R. Stearns, and M. F. Sievers, 1989: Antarctic automatic weather station data for the calendar year 1988. Department of Meteorology, University of WisconsinMadison, 329 pp. [Available from Dept. of Atmospheric and Oceanic Sciences, 1225 W. Dayton St., Madison, WI 53706.]

,,--- , and $\longrightarrow, 1996$ : Antarctic automatic weather station data for the calendar year 1994. Department of Meteorology, University of Wisconsin-Madison, $34 \mathrm{pp}$. [Available from Dept. of Atmospheric and Oceanic Sciences, 1225 W. Dayton St., Madison, WI 53706.]

King, J. C., 1990: Some measurements of turbulence over an Antarctic ice shelf. Quart. J. Roy. Meteor. Soc., 116, 379-400.

-, and W. M. Connolley, 1997: Validation of the surface energy balance over the Antarctic ice sheets in the U.K. Meteorological Office Unified Climate Model. J. Climate, 10, 1273-1287.

Louis, J. F., 1979: A parametric model of vertical eddy fluxes in the atmosphere. Bound.-Layer Meteor., 17, 187-202.

Mahrt, L., and H.-L. Pan, 1984: A two layer model of soil hydrology. Bound.-Layer Meteor., 29, 1-20.

Miller, S. A., 1974: An analysis of heat and moisture budgets of the inversion layer over the Antarctic plateau, for steady state conditions. Ph.D. dissertation, Department of Meteorology, University of Wisconsin-Madison, $68 \mathrm{pp}$. [Available from Dept. of Atmospheric and Oceanic Sciences, 1225 W. Dayton St., Madison, WI 53706.]

Miyakoda, K., and J. Sirutis, 1986: Manual of the e-physics. NOAA/ GFDL, 87 pp. [Available from Geophysical Fluid Dynamics Laboratory, Princeton University, P.O. Box 308, Princeton, NJ 08542.]

Pan, H.-L., 1990: A simple parameterization of evapotranspiration over land for the NMC medium-range forecast model. Mon. Wea. Rev., 118, 2500-2512.

_ - and L. Mahrt, 1987: Interaction between soil hydrology and boundary-layer development. Bound.-Layer Meteor., 38, 185-220.

Parish, T. R., 1988: Surface winds over the Antarctic continent: A review. Rev. Geophys., 26, 169-180.

Phillpot, H. R., and J. W. Zillman, 1970: The surface temperature inversion over the Antarctic continent. J. Geophys. Res., 75, 4161-4169.

Schwerdtfeger, W., 1970: The climate of the Antarctic. World Survey of Climatology, H. E. Landsberg, Ed., Vol. 14, Elsevier, 253355 .

— 1984: Weather and Climate of the Antarctic. Elsevier, 261 pp.

Smiley, V. N., B. M. Whitcomb, B. M. Morley, and J. A. Warburton, 1980: Lidar determinations of atmospheric ice crystal layers at South Pole during clear-sky precipitation. J. Appl. Meteor., 19, 1074-1090.

Stearns, C. R., and G. A. Weidner, 1993: Sensible and latent heat flux estimates in Antarctica. Antarctic Meteorology and Climatology: Studies Based on Automatic Weather Stations, D. H. Bromwich and C. R. Stearns, Eds., Antarctic Research Series, Vol. 61, Amer. Geophys. Union, 109-138.

— , L. M. Keller, G. A. Weidner, and M. Sievers, 1993: Monthly mean climatic data for Antarctic automatic weather stations. Antarctic Meteorology and Climatology: Studies Based on Automatic Weather Stations, D. H. Bromwich and C. R. Stearns, Eds., Antarctic Research Series, Vol. 61, Amer. Geophys. Union, 1-21.

Trenberth, K. E., and J. G. Olson, 1988: An evaluation and intercomparison of global analyses from NMC and ECMWF. Bull. Amer. Meteor. Soc., 69, 1047-1057.

Turner, J., and Coauthors, 1996: The Antarctic First Regional Observing Study of the Troposphere (FROST) project. Bull. Amer. Meteor. Soc., 77, 2007-2032.

Zav'yalova, I. N., 1986: Humidity of air in Antarctica. Climate of Antarctica, I. M. Dolgin, Ed., Oxonian Press Pvt. Ltd., 92-101. 
Copyright of Weather \& Forecasting is the property of American Meteorological Society and its content may not be copied or emailed to multiple sites or posted to a listserv without the copyright holder's express written permission. However, users may print, download, or email articles for individual use. 